Original Paper

\title{
Effect of Temperature on Tarry Material Production of Glucose in Supercritical Water Gasification
}

\author{
Chutinan PROMDEJ, Athika CHUnTANAPUM, and Yukihiko MATSUMURA
}

(Received June 21, 2010)

\begin{abstract}
Our group studied the effects of temperature on the tarry material production of glucose under both subcritical and supercritical water conditions. The glucose solution (1.5 wt\%) was gasified in a tubular reactor at $25 \mathrm{MPa}$ pressure. The reaction temperature ranged from 300 to $450^{\circ} \mathrm{C}$. Gas products, char particles, and liquid products were observed, and the product yields were determined as a function of temperature. Tarry material was only produced under the subcritical water condition $\left(300\right.$ and $\left.350^{\circ} \mathrm{C}\right)$ and was drastically changed or suppressed under the supercritical condition. To explain this, we speculated that the difference in water properties from the subcritical to the supercritical region altered the reaction mechanism. We also determined the kinetic parameters of glucose decomposition pathways by assuming the first-order reaction. The rate constant of overall glucose decomposition conformed to the Arrhenius behavior. The individual rate constant of glucose decomposition in subcritical temperature increased as the temperature rose but decreased in the supercritical condition. Different reaction mechanisms took place under two distinctly different regimes.
\end{abstract}

\section{Key Words}

Tarry material, Glucose, Subcritical water, Supercritical water, Biomass

\section{Introduction}

Biomass continues to be an important candidate as a renewable energy resource. Among the various technologies applicable for biomass conversion, supercritical water gasification (SCWG) is a promising process for gasifying biomass, high moisture content, to desirable products such as $\mathrm{H}_{2}$ and $\mathrm{CH}_{4}$. Water near its critical point has properties very different from those of ambient liquid water ${ }^{1}$. The dielectric constant is much lower, and the number and persistence of hydrogen bonds are both diminished. High-temperature water therefore behaves like many organic solvents, in that organic compounds attain high solubility in near-critical water and complete miscibility with supercritical water. High-temperature water also takes on higher concentrations of $\mathrm{H}^{+}$and $\mathrm{OH}^{-}$ions than liquid water under certain conditions ${ }^{2}$.

Model compounds can be used to effectively elucidate the reaction characteristics for SCWG. The dominant component in most biomass is glucose obtained from a rapid hydrolysis of cellulose. Glucose has drawn the attention

Department of Mechanical Systems Engineering,

Hiroshima University, Graduate School of Engineering

1-4-1 Kagamiyama, Higashi-Hiroshima, Hiroshima 739-8527,

Japan of many researchers as a model compound with interesting decomposition behavior in hot compressed water ${ }^{3) \sim 8)}$. Some recent studies show thermodynamic analysis of glucose in supercritical water gasification from the theoretical point of view ${ }^{910)}$ and catalytic hydrothermal gasification to produce hydrogen rich gas from glucose ${ }^{11) 12}$.

Few studies, nevertheless, cope with reaction mechanism of model biomass in supercritical water gasification. Kabyemela et al. ${ }^{6}$ investigated glucose decomposition with a short residence time at $300-400^{\circ} \mathrm{C}$ under $25-40 \mathrm{MPa}$ pressure. Their experiments identified the key compounds in the liquid effluent and provided data with which to construct a reaction pathway. This has been potentially fruitful, as the kinetics of glucose may be useful in understanding the reaction pathways of cellulose. Matsumura et al. ${ }^{7}$ and Yoshida et al. ${ }^{8)}$ evaluated the kinetics of glucose decomposition in water at supercritical temperature and pressure, respectively.

Our group has also studied tarry material production from glucose in subcritical and supercritical water. With the data

This paper was originally presented at Renewable Energy 2010, Jun. 27 - Jul. 2, 2010, Yokohama, Japan 
obtained, we proposed the reaction kinetics by constructing a reaction network model ${ }^{13) 14}$. This model is still incomplete, however, as it has yet to explain how the reaction temperature affects the reaction kinetics, ionic or freeradical reactions.

In this study we investigate this temperature effect on the tarry material production of glucose gasification under both subcritical and supercritical conditions by measuring the changes in the yields of the reaction products at different temperatures. Then, based on the experimental results, we go on to determine the reaction parameters by assuming the first-order decomposition of glucose.

\section{Experimental}

\subsection{Materials and experimental procedure}

The feedstock used in this study was D-glucose (purity >99.5\%) obtained from Sigma Aldrich and deionized water. The experimental apparatus, shown in Fig. 1, has been reported elsewhere ${ }^{13) 14}$. In brief, an initial concentration of glucose solution (7.5 wt\%) was mixed with the pre-heated water at a 1:4 ratio by volume just before entry into the reactor zone, a point from which sudden heating of the glucose solution to the reaction temperature would be assured. The reacted concentration of glucose was $1.5 \mathrm{wt} \%$ (0.083 $\mathrm{M}$ at room temperature). The reactor was made of SS316 steel and measured $20 \mathrm{~m}$ in length, with inner and outer diameters of $1 \mathrm{~mm}$ and $1.59 \mathrm{~mm}$, respectively. The product effluent discharged from the exit of the reactor was mixed with cold deionized water for rapid cooling. Large solid particles were entrapped inside the inline filters. The liquid effluent (with dispersed char particles) was collected at the liquid sampling point. The gas production rate was measured by the pressure change inside the vacuumed gas sampling port. The gas product was also sampled for a further composition analysis. The system was controlled by a back pressure regulator. The reaction pressure was set $25 \mathrm{MPa}$, the temperature was set in a range from 300 to

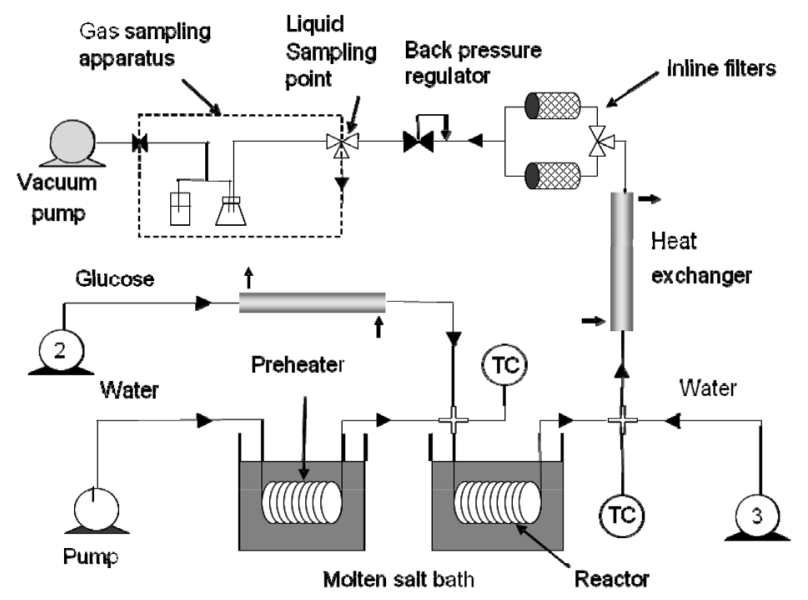

Fig. 1 Experimental apparatus $450^{\circ} \mathrm{C}$, and the residence time was set up to $60 \mathrm{~s}$ (by adjusting the feedstock flow rates).

\subsection{Analytical methods}

The liquid product was analyzed by a total organic carbon (TOC) analyzer to quantify the amounts of carbon in the liquid product (non-purgeable organic carbon or NPOC) and in the dissolved gas product (inorganic carbon or IC). Furfural and 5-hydroxymethylfurfural (5-HMF) were analyzed by HPLC (high-performance liquid chromatography) with an RSpak DE-413L column (Shodex). The analytical conditions were as follows: flowrate $0.5 \mathrm{~mL} / \mathrm{min}$; eluent $0.005 \mathrm{M} \mathrm{HClO}_{4}$ aqueous solution/ $\mathrm{CH}_{3} \mathrm{CN}=90 / 10$; oven temperature $40^{\circ} \mathrm{C}$. Glucose and fructose were analyzed by HPLC using a sugar KS-802 column (Shodex). The analytical conditions were as follows: flow rate $0.8 \mathrm{~mL} / \mathrm{min}$; eluent water; oven temperature $60^{\circ} \mathrm{C}$.

The gas product was analyzed by gas chromatography (GC). $\mathrm{CO}_{2}$ and $\mathrm{CO}$ were detected by GC-TCD (GC with a thermal conductivity detector) with $\mathrm{He}$ as the carrier gas. $\mathrm{CH}_{4}, \mathrm{C}_{2} \mathrm{H}_{4}$, and $\mathrm{C}_{2} \mathrm{H}_{6}$ were detected by GC-FID (GC with a flame ionization detector) with $\mathrm{He}$ as the carrier gas. $\mathrm{H}_{2}$ was detected by GC-TCD with $\mathrm{N}_{2}$ as the carrier gas.

The solid product included particles suspended in the liquid effluent and particles entrapped in the inline filter. The particles in the liquid effluent were obtained by filtering the effluent through a mixed cellulose ester membrane (0.1 $\mu \mathrm{m}$ pore size; Millipore) using vacuum suction. The particles entrapped in the inline filter were taken out with an ultrasonic cleaning device.

\section{Results and Discussions}

\subsection{Products distribution}

The temperature effect on the product yields from the experiment and first-order model can be inferred from Fig. 2, a summary of results from glucose gasification experiments at various temperatures within two ranges, 300-350 ${ }^{\circ} \mathrm{C}$ (subcritical condition) and $400-450^{\circ} \mathrm{C}$ (supercritical condition).

Product yields of glucose decomposition from the experimental results were calculated on the basis of the carbon content in the glucose feedstock:

$$
\text { Product yield }=\frac{\text { Carbon content in product }[\mathrm{mol}-\mathrm{C} / \mathrm{L}]}{(0.83 \mathrm{~mol} / \mathrm{L}) \times(6 \mathrm{~mol}-\mathrm{C} / \mathrm{mol})}
$$

The total carbon balance of this work was higher than $90 \%$ in most cases.

The glucose decomposition (see Fig. 2) was rapid, and it accelerated as the temperature rose. Glucose was almost completely decomposed in $60 \mathrm{~s}$ even at the lowest subcriti- 
(a) Glucose

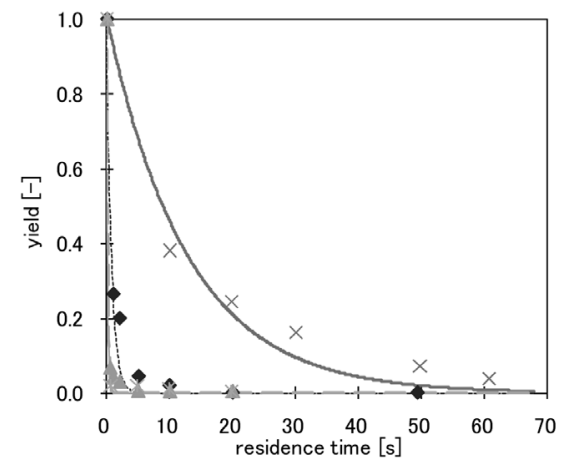

(b) $\mathrm{TOC}$

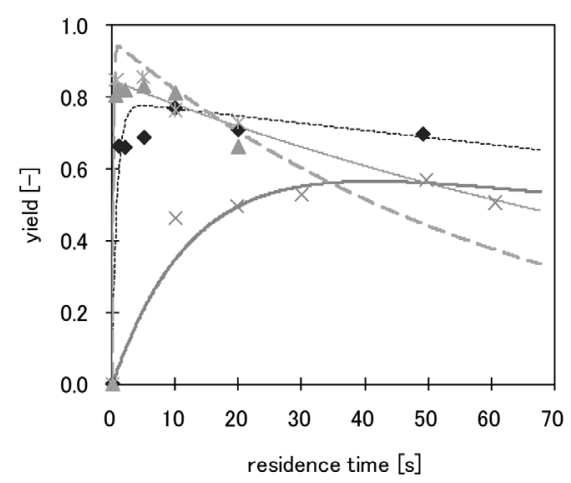

(c) Gas

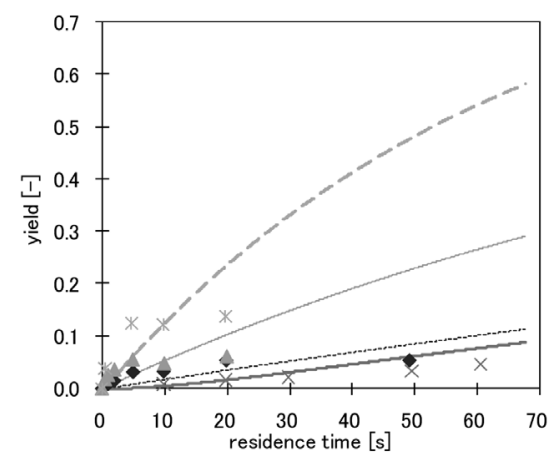

(g) Char

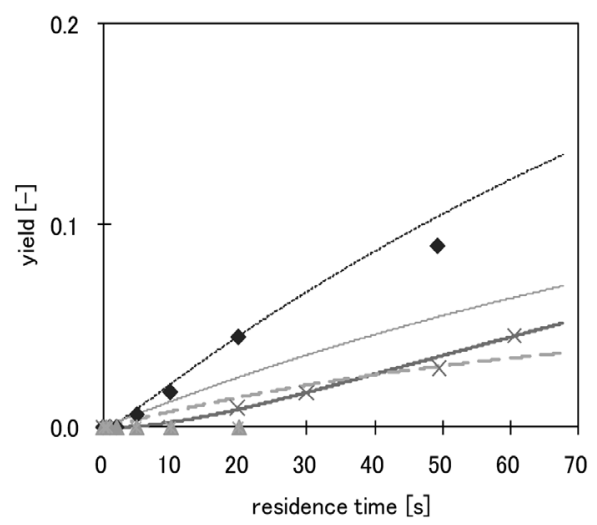

(d) Fructose

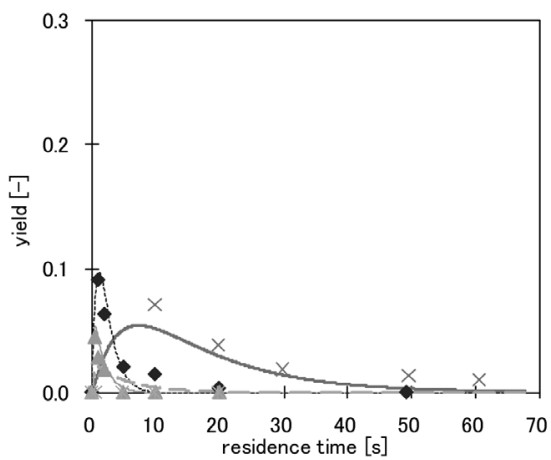

(e) 5-HMF

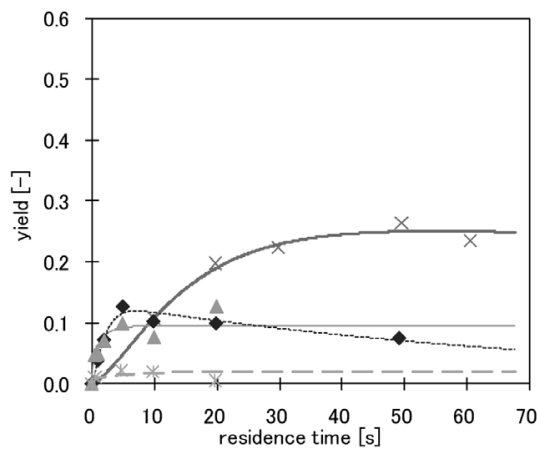

(f) Furfural

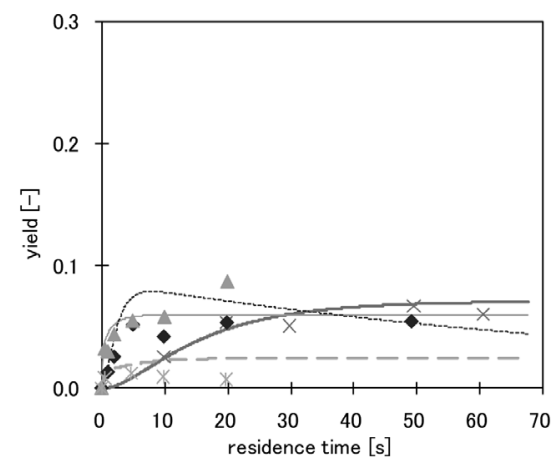


cal temperature of $300^{\circ} \mathrm{C}$, and in only $0.5 \mathrm{~s}$ at the highest supercritical temperature of $450^{\circ} \mathrm{C}$. The change in the water properties as the reaction temperature rose from a subcritical to supercritical water condition resulted in an increase in the gas yield. Kruse and Gawlick ${ }^{15)}$ has demonstrated that the lower density of water in a supercritical condition favors free-radical reactions indispensable to the production of the gaseous product.

Temperature had significant effects on the yields of fructose, 5-HMF, furfural and water-soluble products (TOC). Fructose, an isomer of glucose, was both rapidly formed and rapidly decomposed at increasing temperature up to the maximum temperature under the supercritical condition $\left(450^{\circ} \mathrm{C}\right)$. The yields of 5 -HMF and furfural decreased as temperature rose. It may be that 5-HMF and furfural, the intermediate compounds of the glucose decomposition were further decomposed to other products. The TOC yield, however, rapidly increased at the higher temperature and also declined for the long residence time.

Even the tarry material production was confined to the subcritical region, and the yield of tarry material increased with rising temperature within the subcritical region. This implies that tarry material production is based on the same mechanism in the subcritical region, but that it changes or completely disappears in the supercritical region. In view of the drastic change in the pattern of tarry material production from the subcritical to supercritical conditions, it may be reasonable to assume that the low dielectric constant under supercritical temperatures leads to the freeradical reactions. The ionic reactions necessary to form the aromatic compounds that facilitate the tarry material production are inhibited.

\subsection{Reaction rates}

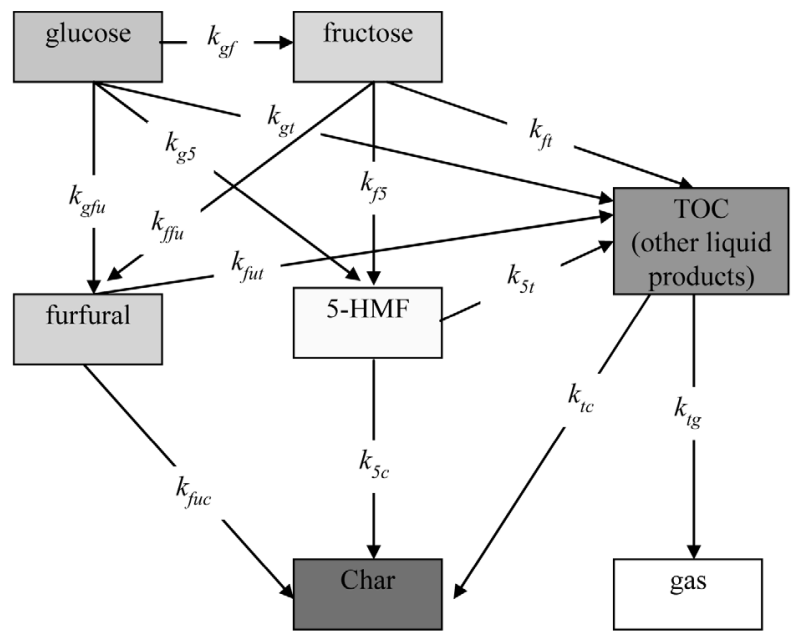

Fig. 3 Proposed formation pathways of glucose char particles (assuming all reactions are first order)
The reaction kinetics were evaluated from the reaction pathway observed, as shown in Fig. 3. We assumed that all the reaction orders of glucose decomposition were unity. The glucose decomposition was fit using the respective differential equations below:

$$
\begin{aligned}
& \left.\frac{\mathrm{d}[\text { glucose }]}{\mathrm{dt}}=-\left(\mathrm{kgf}_{\mathrm{gf}}+\mathrm{k}_{\mathrm{gfu}}+\mathrm{kgt}_{\mathrm{gt}}+\mathrm{k}_{\mathrm{g} 5}\right) \text { [glucose }\right] \\
& \left.\frac{\mathrm{d}[\text { fructose }]}{\mathrm{dt}}=\mathrm{kgf}_{\mathrm{gf}}[\text { glucose }]-\left(\mathrm{k}_{\mathrm{f} 5}+\mathrm{k}_{\mathrm{ffu}}+\mathrm{k}_{\mathrm{ft}}\right) \text { [fructose }\right]
\end{aligned}
$$

$$
\frac{\mathrm{d}[5-\mathrm{HMF}]}{\mathrm{dt}}=\mathrm{kg}_{\mathrm{g} 5}[\text { glucose }]+\mathrm{k}_{\mathrm{f} 5}[\text { fructose }]-\mathrm{k}_{5 \mathrm{t}}[5-\mathrm{HMF}]
$$$$
-\mathrm{k}_{5 c}[5-\mathrm{HMF}]
$$

$\frac{\mathrm{d}[\text { furfural }]}{\mathrm{dt}}=\mathrm{kgfu}_{\mathrm{gfu}}[$ glucose $]+\mathrm{k}_{\mathrm{ffu}}[$ fructose $]$

$$
-\left(\mathrm{k}_{\text {fut }}+\mathrm{k}_{\text {fuc }}\right) \text { [furfural] }
$$

$\frac{\mathrm{d}[\mathrm{TOC}]}{\mathrm{dt}}=\mathrm{kgt}_{\mathrm{gt}}[$ glucose $]+\mathrm{k}_{\mathrm{ft}}[$ fructose $]+\mathrm{k}_{5 t}[5-\mathrm{HMF}]$

$$
+\mathrm{k}_{\text {fut }}[\text { furfural }]-\mathrm{ktc}_{\mathrm{tc}}[\mathrm{TOC}]-\mathrm{k}_{\mathrm{tg}}[\mathrm{TOC}]
$$

$\frac{\mathrm{d}[\mathrm{char}]}{\mathrm{dt}}=\mathrm{k}_{\mathrm{fuc}}[$ furfural $]+\mathrm{k}_{5 \mathrm{c}}[5-\mathrm{HMF}]+\mathrm{k}_{\mathrm{tc}}[\mathrm{TOC}]$

$\frac{\mathrm{d}[\mathrm{gas}]}{\mathrm{dt}}=\mathrm{ktg}_{\mathrm{tg}}[\mathrm{TOC}]$

where

[glucose $]=$ glucose concentration $(\mathrm{mol}-\mathrm{C} / \mathrm{L})$,

[fructose $]=$ fructose concentration $(\mathrm{mol}-\mathrm{C} / \mathrm{L})$,

$[5-\mathrm{HMF}]=5-\mathrm{HMF}$ concentration $(\mathrm{mol}-\mathrm{C} / \mathrm{L})$,

[furfural $]=$ furfural concentration $(\mathrm{mol}-\mathrm{C} / \mathrm{L})$,

$[\mathrm{TOC}]=$ lumped carbon concentration of the other liquid products (mol-C/L),

[char $]=$ char concentration $(\mathrm{mol}-\mathrm{C} / \mathrm{L})$,

[gas] $=$ carbon concentration in the gas product (mol-C/ L),

$\mathrm{t}=$ residence time $(\mathrm{s})$.

This work was determined by the rate constants of reactions from glucose to the decomposition products by the least squares method, as shown in Table 1, Fig. 4, and Fig. 5. The glucose decomposition behavior is related to the Arrhenius characteristic. The overall decomposition rate of glucose $(\mathrm{kg})$ was proportional to the temperature. The Arrhenius plot for the present experiments gave a pre-exponential factor of $1.39 \times 10^{8} \mathrm{~S}^{-1}$ and an activation energy of $99.23 \mathrm{~kJ} / \mathrm{mol}$. These parameters are consistent with those of the previous studies shown in Fig. 4. The activation energies of 121 and $96 \mathrm{~kJ} / \mathrm{mol}$ were determined from the work by Matsumura et al. ${ }^{7)}$ and Kabyemela et al. ${ }^{5)}$, respectively.

Though the overall glucose decomposition follows the Arrhenius equation, as evinced by the Arrhenius plot in Fig. 4, some individual pathways may diverge. As shown 
Table 1 Kinetic parameters obtained from the first order model for glucose decomposition

\begin{tabular}{cccccc}
\hline $\begin{array}{c}\mathrm{T} \\
\text { (deg C) }\end{array}$ & $300^{*}$ & $350^{*}$ & $400^{*}$ & 450 \\
\hline & $\mathrm{k}$ & $\mathrm{k}$ & $\mathrm{k}$ & $\mathrm{k}$ & $\alpha$ \\
\multicolumn{5}{c}{$\left(\mathrm{s}^{-1}\right)$} \\
\hline gf & $2.09 \mathrm{E}-02$ & $2.21 \mathrm{E}-01$ & $2.86 \mathrm{E}-01$ & $1.30 \mathrm{E}-01$ & 1 \\
gfu & 0 & 0 & $1.60 \mathrm{E}-01$ & $7.18 \mathrm{E}-02$ & 1 \\
gt & $5.13 \mathrm{E}-02$ & $9.30 \mathrm{E}-01$ & $3.60 \mathrm{E}+00$ & $5.31 \mathrm{E}+00$ & 1 \\
g5 & $6.00 \mathrm{E}-03$ & $3.27 \mathrm{E}-02$ & $2.15 \mathrm{E}-01$ & $5.23 \mathrm{E}-02$ & 1 \\
f5 & $1.62 \mathrm{E}-01$ & $3.30 \mathrm{E}-01$ & $3.82 \mathrm{E}-01$ & $9.00 \mathrm{E}-02$ & 1 \\
ffu & $5.94 \mathrm{E}-02$ & $2.74 \mathrm{E}-01$ & $1.91 \mathrm{E}-01$ & $9.32 \mathrm{E}-02$ & 1 \\
ft & 0 & 0 & 0 & 0 & 1 \\
$5 t$ & 0 & $2.45 \mathrm{E}-05$ & 0 & 0 & 1 \\
$5 \mathrm{c}$ & $1.59 \mathrm{E}-03$ & $1.28 \mathrm{E}-02$ & 0 & 0 & 1 \\
fut & 0 & $9.94 \mathrm{E}-03$ & 0 & 0 & 1 \\
fuc & 0 & 0 & 0 & 0 & 1 \\
tc & $9.35 \mathrm{E}-04$ & $1.29 \mathrm{E}-03$ & $1.60 \mathrm{E}-03$ & $9.30 \mathrm{E}-04$ & 1 \\
tg & $2.69 \mathrm{E}-03$ & $2.35 \mathrm{E}-03$ & $6.64 \mathrm{E}-03$ & $1.46 \mathrm{E}-02$ & 1 \\
g & $7.81 \mathrm{E}-02$ & $1.18 \mathrm{E}+00$ & $4.26 \mathrm{E}+00$ & $5.56 \mathrm{E}+00$ & 1 \\
\hline
\end{tabular}

* Previous study (Chuntanapum and Matsumura (2010))

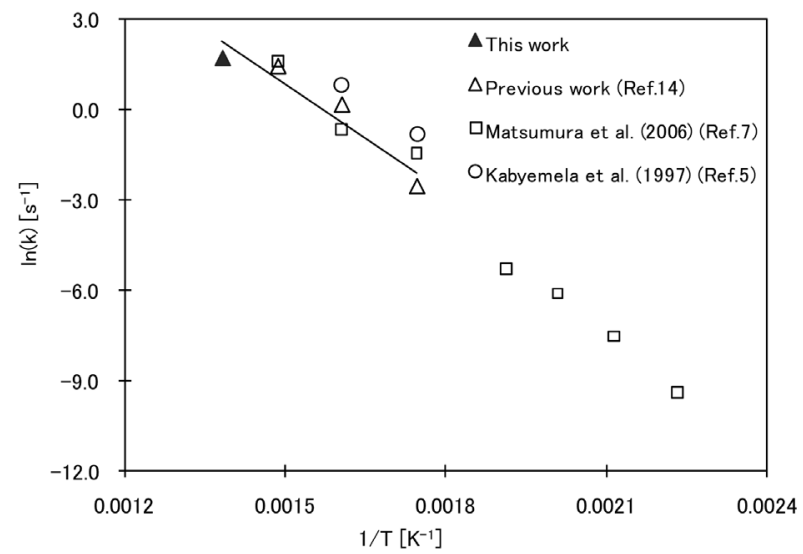

Fig. 4 Arrhenius plot of the reaction rate constant of glucose $\left(\mathrm{kg}_{\mathrm{g}}\right)$ compare with other works

in Fig. 5 , the rate of the reactions $\mathrm{kgf}_{\mathrm{gf}} \mathrm{kgfu}_{\mathrm{g}} \mathrm{k}_{\mathrm{g} 5}, \mathrm{k}_{\mathrm{ffu}}, \mathrm{k}_{\mathrm{f}}, \mathrm{k}_{5 \mathrm{t}}$, $\mathrm{k}_{5 \mathrm{c}}$, $\mathrm{k}_{\mathrm{fut}}$, and $\mathrm{k}_{\mathrm{tc}}$ do not continue to increase with temperature above the critical point. The rate of the reaction $\mathrm{k}_{\mathrm{tg}}$, however, conforms to the Arrhenius behavior. In supercritical condition, they were clearly seen that the TOC gasification as free-radical reaction was prompted meanwhile other individual reactions were suppressed. Matsumura et al. ${ }^{7)}$ have suggested that the difference in the water properties from the subcritical to the supercritical region should alter the reaction mechanism. The ionic reaction in the subcritical condition should be promoted, while the radical reaction in the subcritical condition should be demoted. (a)

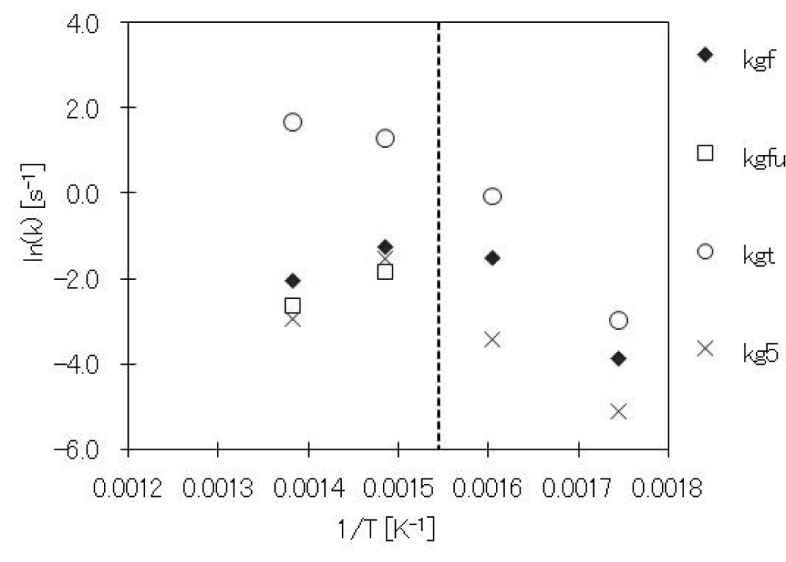

(b)

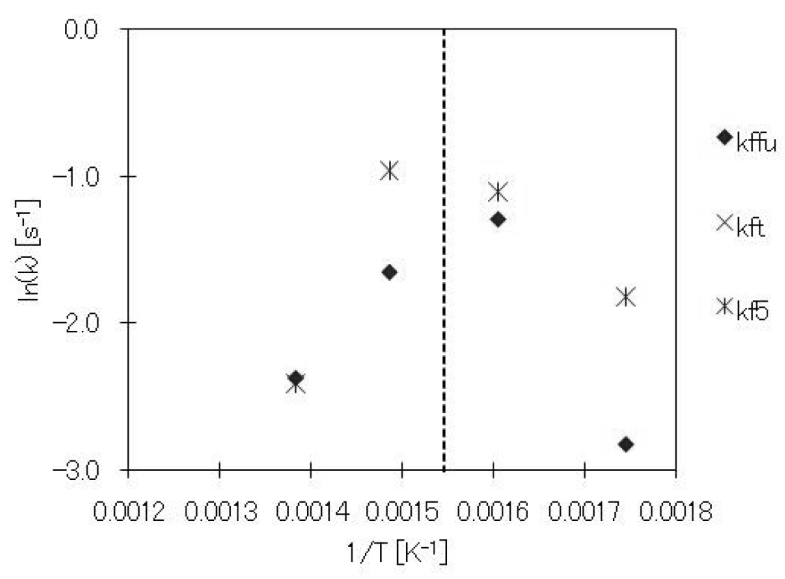

(c)

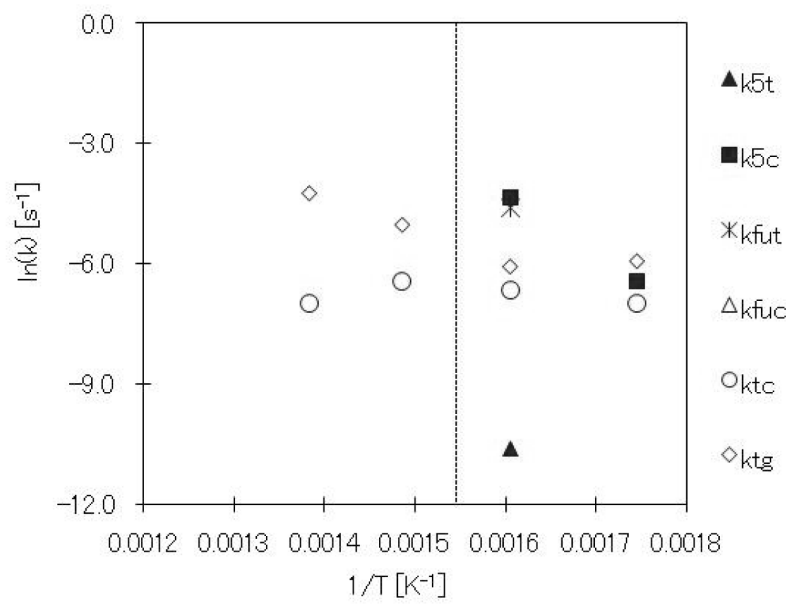

Fig. 5 Arrhenius plot of the reaction rate constant from the first order model for the glucose decomposition

\section{Conclusions}

The formation pathways for the tarry material production of glucose were examined under subcritical and supercritical water conditions. The tarry formation only occurred under the subcritical condition. Under the supercritical condition it was drastically suppressed. To 
explain this drastic change in the yield, we speculated that the low dielectric constant may lead to further free-radical reactions to a gaseous product, or that tarry material may behave like solvent in the supercritical region.

The reaction rate of glucose decomposition in water was also determined under subcritical and supercritical conditions. While some individual rate constants for glucose decomposition may have diverged, the overall rate of glucose decomposition conformed to the Arrhenius characteristic. The different water properties in the subcritical and supercritical conditions may have affected the reaction mechanism.

\section{References}

1) Akiya, N., Savage, P. E., Chem.Rev., 102, 2725-2750 (2002)

2) Savage, P. E., Chem. Rev., 99, 603-621 (1999)

3) Knezevic, D., Swaaij, W. P. M. van, Kersten, S. R. A., Ind. Eng. Chem. Res., 48, 4731-4743(2009)

4) Sinag, A., Kruse, A., Rathert, J., Ind. Eng. Chem. Res., 43, 502-508 (2004)

5) Kabyemela, B. M., Adschiri, T., Malaluan, R. M., Arai, K., Ind. Eng. Chem. Res., 36, 1552-1558(1997)
6) Kabyemela, B. M., Adschiri, T., Malaluan, R. M., Arai, K., Ind. Eng. Chem. Res., 38, 2888-2895(1999)

7) Matsumura, Y., Yanachi, S., Yoshida, T., Ind. Eng. Chem. Res., 45, 1875-1879(2006)

8) Yoshida, T., Yanachi, S., Matsumura, Y., J. Jpn. Inst.Energy, 86, 700-706 (2007)

9) Yan, Q., Guo, L., Lu, Y., Energy Convers. Manage., 47, 15151528(2006)

10) Voll, F. A. P., Rossi, C. C. R. S., Silva, C., Guirardello, Souza, R. O. M. A, Cabral, V. F., Cardozo-Filho, L., Int. J. Hydrogen Energy, 34, 9737-9744(2009)

11) Fang, Z., Minowa, T., Fang, C., Smith, R. L. Jr., Inomata, H., Kozinski, J. A., Int.J. Hydrogen Energy, 33, 981-990 (2008)

12) Youssef, E. A., Chowdhury, M. B. I., Nakhla, G., Charpentier, P., Int. J. Hydrogen Energy, 35, 5034-5042 (2010)

13) Chuntanapum, A., Matsumura, Y., Proc. 2009 AIChE Annual Meeting, Nov. 8-13, 2009, Nashville, USA, 477c

14) Chuntanapum, A., Matsumura, Y., Ind. Eng. Chem.Res., 49 , 4055-4062 (2010)

15) Kruse, A., Gawlik, A., Ind. Eng. Chem. Res., 42, 267-279 (2003) 